\title{
The surface modification of boron nitride particles
}

\author{
Shahla Daneshmehr, Frida Román, John M Hutchinson* \\ Departament de Màquines i Motors Tèrmics, ESEIAAT, Universitat Politècnica de Catalunya, \\ C/Colom 11, 08222 Terrassa, Spain \\ Corresponding author: e-mail hutchinson@mmt.upc.edu \\ Tel: +34937398123 \\ ORCID: Román 0000-0001-7435-2402; Hutchinson 0000-0003-0743-1260
}

\begin{abstract}
Composites of epoxy and boron nitride $(\mathrm{BN})$ have been investigated for application as insulated metal substrates with high thermal conductivity. BN particles, nominally in the form of platelets, with an average size of $6 \mu \mathrm{m}$, and agglomerates, with an average size of $120 \mu \mathrm{m}$, have been used. First, composites were fabricated using these particles "as received", without any surface treatment. Different proportions of these BN particles, up to a volume percentage of approximately $34 \%$, were mixed with a stoichiometric epoxy-thiol system. The cure kinetics was investigated by differential scanning calorimetry (DSC), and the thermal conductivity of fully cured samples was measured. Having established the performance of epoxy-BN composites with untreated particles, the effect of surface treatment was then investigated. Two procedures were used to attach a silane coupling agent to the BN particles, both with and without previously treating the BN with a sodium hydroxide solution. Infra-red spectroscopy and thermogravimetric analysis were used to assess whether or not the silane had been attached to the $\mathrm{BN}$ particles, and the effect of the surface treatment on the cure kinetics was studied by DSC. Although the cure kinetics suggested that the surface treatment was more effective for the $6 \mu \mathrm{m}$ particles than for the $120 \mu \mathrm{m}$ agglomerates, it did not lead to an increase in the thermal conductivity except for one isolated case, while scanning electron microscopy showed that the coupling agent was not attached to the BN particles. It is concluded that truly platelet-shaped particles are necessary for effective surface treatment.
\end{abstract}

Keywords: boron nitride; epoxy composites; thermal conductivity; differential scanning calorimetry (DSC); surface treatment 


\section{Introduction}

Modern microelectronic devices, which operate at increasingly higher powers and frequencies, and hence which generate ever greater amounts of heat, require ever more effective means of heat removal in order that their service lifetime should not be significantly affected. This places quite severe demands on the dielectric layer separating the device from the metal heat sink: this adhesive layer must be electrically insulating, highly thermally conducting, and easily fabricated. This combination of requirements is usually met by a composite material consisting of an epoxy matrix filled with one or more of several highly thermally conducting ceramic materials. Nonoxides such as boron nitride (BN), aluminium nitride ( $\mathrm{AlN})$, silicon nitride $\left(\mathrm{Si}_{3} \mathrm{~N}_{4}\right)$ or silicon carbide ( $\mathrm{SiC})$ are generally preferred as they tend to have higher thermal conductivities than oxides such as alumina $\left(\mathrm{Al}_{2} \mathrm{O}_{3}\right)$ and silica $\left(\mathrm{SiO}_{2}\right)$ [1]. The addition of such fillers can increase the thermal conductivity of the composite material by at least an order of magnitude in comparison with that of the original printed circuit board technology $(0.2 \mathrm{~W} / \mathrm{mK})$, and nowadays values of $3.0 \mathrm{~W} / \mathrm{mK}$ are quite commonplace. Nevertheless, still higher values would be advantageous, and there has been considerable effort recently devoted to this end [1-3]. In the discussion that follows we limit ourselves to composites in which the filler is BN.

There are a number of parameters which contribute to the thermal conductivity of these filled epoxy composite systems. The most obvious is the filler content, and the almost universal observation, at least up to about $50 \mathrm{vol} \%$ filler, is that the thermal conductivity increases, and increasingly rapidly, as the filler content increases [3]. However, there is a practical limit to the filler content, as the epoxy-filler mixture becomes a highly viscous paste at contents greater than 40 to $50 \mathrm{vol} \%$, which cannot easily be used in a simple way, for example without the use of solvents. Furthermore, it is very difficult to eliminate the air bubbles from these highly viscous pastes, and the resulting voids lead to a reduction in the thermal conductivity, which is the opposite effect from that intended by the high filler content.

The size and shape of the filler particles also has an influence on the thermal conductivity for a given filler content, but the effect is not entirely clear. Most authors report an increase in thermal conductivity with increasing particle size for the same filler content [e.g. 4-9], although sometimes this is confounded by the different shapes of the particles [10-12]. On the other hand, some authors report that there is no significant effect of particle size [13], while others even report a decrease in thermal conductivity with increasing particle size $[14,15]$. 
Another parameter which plays an important role in determining the thermal conductivity of these composites is the presence or otherwise of a coupling agent or the use of surface treatments of the filler particles in order to enhance the interface between epoxy matrix and filler. This aspect remains rather controversial, and is complicated by the wide variety of surface treatments and coupling agents that are used, including different acids and sodium hydroxide for the former and various types of silane for the latter, as well as by variations in the treatment procedures and proportions. Many authors report increases of typically between $15 \%$ and $25 \%$ in the thermal conductivity for such treatments [e.g. 7,9,13,16-19], while some increases are significantly larger $[20,21]$. In contrast, there are reports that such surface treatments have little or no effect on the thermal conductivity [8,22-26], and Kim and Kim [27] find that - OH treatment of their particles leads to an increased thermal conductivity whereas the use of silane reduces it.

It is this last aspect, the effects of surface treatments and coupling agents, that we investigate in the present work. In particular, our approach is based on that used by Kim et al [7], who find that the thermal conductivity of their epoxy-BN composite system can increase by as much as $40 \%$ when the BN particles are treated. These workers essentially follow a procedure patented earlier by Ishida [28] in which the hexagonal BN platelets are first suspended in a sodium hydroxide solution in order to attach hydroxide ions onto the surface, and then these BN hydroxide particles are modified by a sol-gel reaction using a silane coupling agent terminated by an epoxy group. The presence of this epoxy group creates a stronger interface between the epoxy matrix and the particles, resulting in a higher thermal conductivity.

In fact, the surfaces of these $\mathrm{BN}$ platelets are essentially unreactive, and it is at the edges of these particles that the coupling agent is considered to react. This has important implications as regards the shape of the BN filler. If the filler is in the form of hexagonal platelets there are many edges available for reaction, a larger amount the smaller is the platelet size. On the other hand, if the filler is in the form of agglomerates there will be many fewer edges for a given amount of BN. It would therefore be expected that the improvement in the thermal conductivity of an epoxyBN composite in which the BN particles have been surface treated in order to attach a silane coupling agent will depend on the type of BN particle used: particles in the form of platelets will be expected to give a higher thermal conductivity than agglomerates for the same vol\% of the filler. The objective of this paper is to clarify these ideas by measuring the thermal conductivity of epoxy-BN composites in which the epoxy is cured with a thiol, and the BN particles of 
different shapes, namely platelets and approximately spherical agglomerates, are treated in order to attach a silane coupling agent. In addition, the cure kinetics of each of these composite systems will be studied by differential scanning calorimetry, as it was found earlier that there is a strong correlation between the cure kinetics and the thermal conductivity for epoxy-BN composites cured with a thiol $[3,29]$.

\section{Materials and Methods}

\subsection{Materials}

The epoxy resin used was diglycidyl ether of bisphenol-A, DGEBA (Araldite GY 240, Huntsman Advanced Materials, Salt Lake City, Utah, USA, $182 \mathrm{~g} / \mathrm{eq}$, density $1.17 \mathrm{~g} / \mathrm{cm}^{3}$ ), with a thiol, pentaerythritol tetrakis (3-mercaptopropionate) (Sigma-Aldrich, Saint Louis, MO, USA, 488.66 $\mathrm{g} / \mathrm{mol}$, density $1.28 \mathrm{~g} / \mathrm{cm}^{3}$ ) as the cross-linking agent. For cross-linking with the thiol, a latent initiator was used, encapsulated imidazole LC-80 (Technicure, A\&C Catalysts, Linden, NJ, USA) in the form of powder. Two different grades of BN filler particles were used: hexagonal platelets, with average particle size of $6 \mu \mathrm{m}$, and approximately spherical agglomerates with an average particle size of $120 \mu \mathrm{m}$. The $6 \mu \mathrm{m}$ particles were kindly provided by Benmayor S.A. (Barcelona, Spain) and the $120 \mu \mathrm{m}$ agglomerates (PCTL5MHF) were obtained from Saint Gobain Boron Nitride (Amherst, NY, USA). Scanning electron microscopy (SEM) micrographs of the as-received particles are shown in Figures $1 \mathrm{a}$ and $1 \mathrm{~b}$ for the $6 \mu \mathrm{m}$ platelets and $120 \mu \mathrm{m}$ agglomerates, respectively, at two different magnifications.
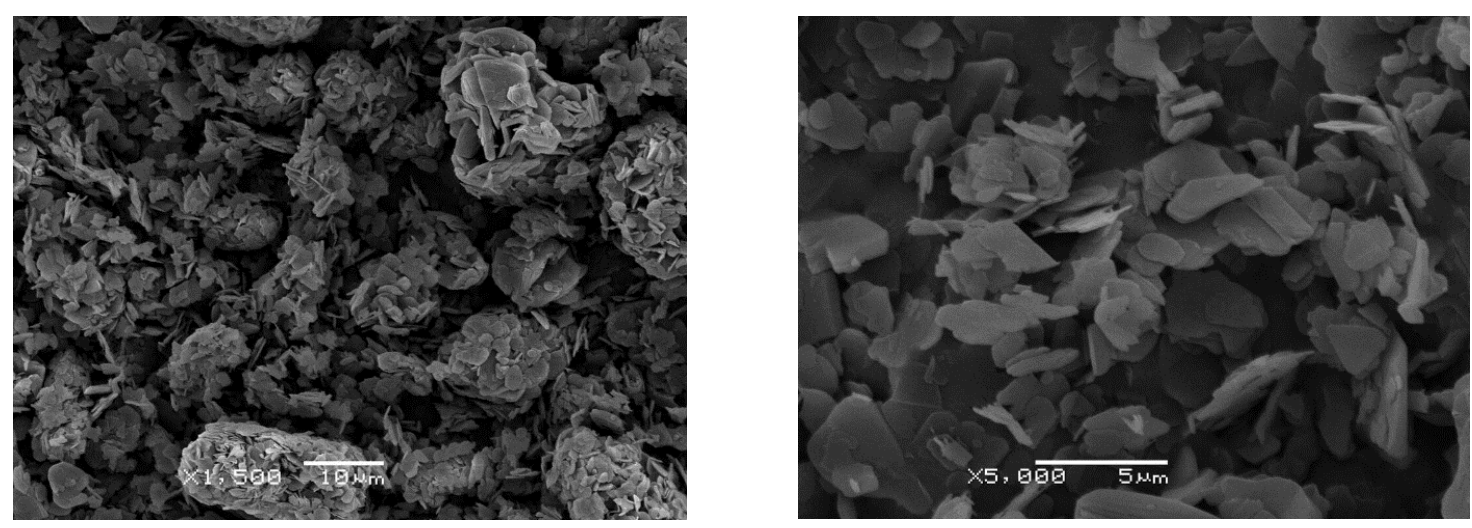

Figure 1a. SEM micrographs of $6 \mu \mathrm{m}$ BN particles. 

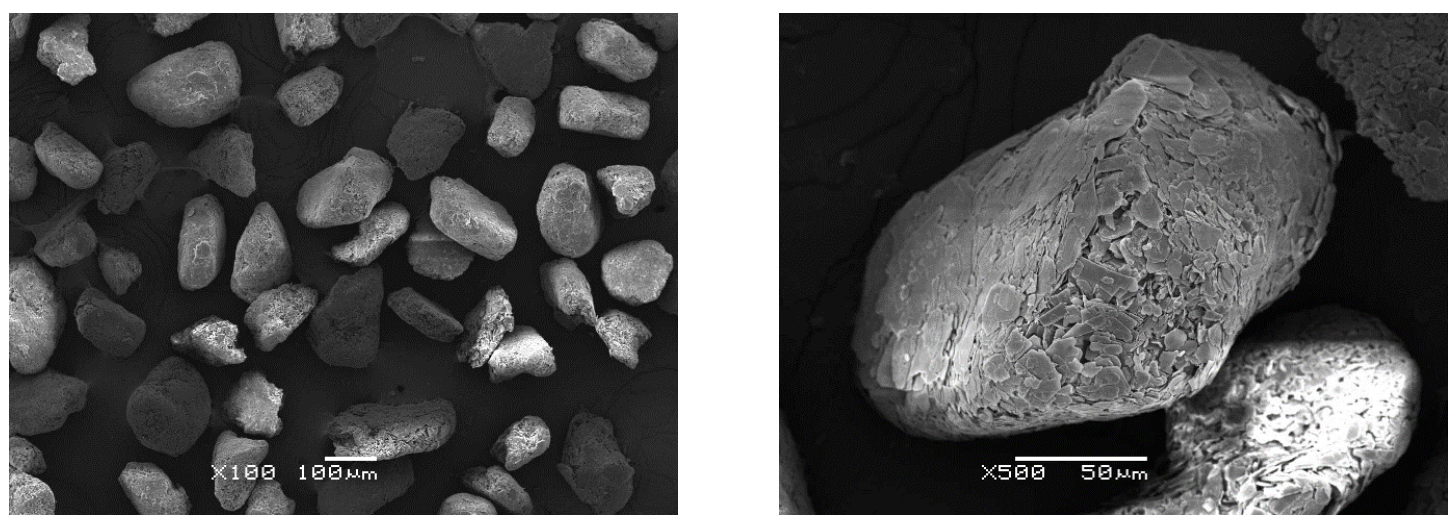

Figure 1b. SEM micrographs of $120 \mu \mathrm{m}$ agglomerates.

Although the $6 \mu \mathrm{m}$ particles are nominally platelets, it can be seen from Figure 1a that there is a certain degree of agglomeration. Nevertheless, as seen in Figure 1a at the higher magnification, there are regions in which the particles are essentially independent and present a substantial amount of edges for subsequent modification. In contrast, Figure $1 \mathrm{~b}$ shows very clearly that the $120 \mu \mathrm{m}$ particles are dense agglomerates for which very few platelet edges are available for modification.

The silane coupling agent was 3-glycidoxypropyltrimethoxysilane (GPTMS) (Sigma-Aldrich, Saint Louis, MO, USA, $488.66 \mathrm{~g} / \mathrm{mol}$, density $1.28 \mathrm{~g} / \mathrm{cm}^{3}$ ).

\subsection{Methods}

\subsubsection{Surface modification of $B N$}

The BN particles, either $6 \mu \mathrm{m}$ or $120 \mu \mathrm{m}$, were suspended in a 5 molar sodium hydroxide, $\mathrm{NaOH}$, solution at $104{ }^{\circ} \mathrm{C}$ for $24 \mathrm{~h}$ in order to attach hydroxide ions onto the surfaces. The particles were rinsed with deionised water and filtered several times before being dried in a furnace at $100{ }^{\circ} \mathrm{C}$ for 2-5h, cooled to room temperature, and then stored in desiccators prior to subsequent use. These $\mathrm{NaOH}$-treated $6 \mu \mathrm{m}$ and $120 \mu \mathrm{m}$ particles are denoted BN6-NaOH and BN120-NaOH respectively. For the subsequent silane treatment, a measured amount of GPTMS silane ( $4 \mathrm{wt} \%$, $5 \mathrm{wt} \%$ and $10 \mathrm{wt} \%$ with respect to the weight of BN powder) was added to $150 \mathrm{~mL}$ of deionised water, into which $15 \mathrm{~g}$ of the $\mathrm{NaOH}$-treated $\mathrm{BN}$ particles was added. The solution was heated at 
$65{ }^{\circ} \mathrm{C}$ for $1 \mathrm{~h}$ and ultrasonication (sonication bath with frequency $40 \mathrm{~Hz}$, Branson 3510, USA) was simultaneously applied to achieve a sufficiently homogeneous dispersion. The resultant powder was then obtained by filtration, rinsed with deionised water, filtered a further three times and finally dried in a furnace. These silane-treated $6 \mu \mathrm{m}$ and $120 \mu \mathrm{m}$ BN particles are denoted BN6-Si4\% and BN120-Six\% respectively; $x$ represents the silane concentration, which was $4 \%$, $5 \%$ and $10 \%$ for the BN120 samples but only the $4 \%$ concentration was used for the BN6 particles.

\subsubsection{Epoxy-BN sample preparation}

Having treated the BN particles, the different epoxy-BN composite materials were prepared in the usual way $[3,29]$. The LC-80 initiator, the smallest component and in a proportion of 2.0 parts per hundred resin (phr), was mixed with the thiol, in an amount calculated to maintain a stoichiometric ratio with the epoxy resin (approximately 60:40 epoxy/thiol by mass). The epoxy resin was then added, mixed thoroughly, and finally the $\mathrm{BN}$ filler was added in the proportion required, which ranged from $30 \%$ to $60 \%$ by weight, with respect to the combined weight of the $\mathrm{BN}$ and epoxy. All these components were mixed manually for about $10 \mathrm{~min}$, until the appearance was homogenous. The mixture was then placed in a vacuum chamber to degas, at room temperature and at a pressure of less than $26 \mathrm{hPa}$, for about $15 \mathrm{~min}$. A complete description of all the compositions used is given in Table 1 .

Table 1. Composition of samples for 30, 50 and $60 \mathrm{wt} \% \mathrm{BN}$ (for $x=6 \mu \mathrm{m}$ and $120 \mu \mathrm{m}$ ).

\begin{tabular}{|l|l|l|l|l|}
\hline \multirow{2}{*}{ Samples } & \multicolumn{4}{l|}{ Compositions by weight } \\
\cline { 2 - 5 } & epoxy & BN & thiol & LC-80 \\
\hline ETL & 60 & 0 & 40 & 1.2 \\
\hline ETLBN $x-30$ & 60 & 25.7 & 40 & 1.2 \\
\hline ETLBN $x-50$ & 60 & 60 & 40 & 1.2 \\
\hline ETLBN $x-60$ & 60 & 90 & 40 & 1.2 \\
\hline
\end{tabular}




\subsubsection{Differential Scanning Calorimetry (DSC)}

The cure reaction kinetics was determined by differential scanning calorimetry (DSC) in nonisothermal (constant heating rate) mode. Small samples of about $10 \mathrm{mg}$ of the uncured epoxyBN composite mixture were carefully weighed (Mettler Toledo analytical balance, AE 163, Greifensee, Switzerland, reproducibility $0.02 \mathrm{mg}$ ) into an aluminium capsule and crimped with a lid. A conventional DSC (DSC821e, Mettler Toledo) equipped with a robot sample handler and intracooler (Haake EK90/MT, Vreden, Germany) was used, with a dry nitrogen gas flow of $50 \mathrm{~mL} / \mathrm{min}$. The data evaluation was performed with the STARe software (Mettler Toledo, Greifensee, Switzerland), and the DSC was calibrated for both heat flow and temperature using indium.

For the non-isothermal cure experiments, the sample was introduced by the robot into the DSC furnace at room temperature, cooled at $20 \mathrm{~K} / \mathrm{min}$ to $-65^{\circ} \mathrm{C}$, and then heated at the required constant rate $(2,5$ or $10 \mathrm{~K} / \mathrm{min})$ to $200{ }^{\circ} \mathrm{C}$. The cure kinetics is characterized by the temperature, $T_{\mathrm{p}}$, at which the heat flow is a maximum, and by the exothermic heat of reaction, $\Delta H$, obtained from the area under the cure curve. In addition, the glass transition temperature of the uncured mixture, $T_{\mathrm{g} 0}$, was determined, occurring at a temperature well below that at which the cure reaction starts, as a check on the reproducibility of the measurements. After the non-isothermal cure experiment, a second scan (non-isothermal, at $10 \mathrm{~K} / \mathrm{min}$ ) was performed to determine the final glass transition temperature, $T_{\mathrm{g} \infty}$, of the fully cured sample.

\subsubsection{Thermal conductivity measurements}

The measurements of the thermal conductivity were made using the Transient Hot Bridge method (Linseis, GmbH, THB-100, Selb, Germany) and a Kapton Hot Point sensor (Linseis) calibrated with polymethyl methacrylate (PMMA), borosilicate crown glass, marble, a Ti-Al alloy, and titanium, covering a range of thermal conductivities from $0.2 \mathrm{~W} / \mathrm{mK}$ to above 10 $\mathrm{W} / \mathrm{mK}$. For the measurement of thermal conductivity, the epoxy-BN composite samples were prepared by casting the uncured epoxy-BN mixture into silicone moulds, $10 \mathrm{~mm} \times 40 \mathrm{~mm} \times 4$ $\mathrm{mm}$. In order to perform these measurements, two samples of any given composition were used; the surfaces (10 $\mathrm{mm} \times 40 \mathrm{~mm}$ faces) of each sample were carefully polished manually using emery paper (120, 400, and 600 grit size, sequentially), in order to give flat and smooth surfaces for contact with the Kapton sensor. The sensor was clamped between the two flat faces of the 
two samples, using a manual screw-actuated press. The THB-100 instrument applies a controlled heating power, typically $50 \mathrm{~mW}$, to the sensor, which measures the resulting temperature change in the sample as a function of time; the higher the thermal conductivity of the sample, the more rapidly the heat is dissipated, and the smaller the corresponding temperature rise, $\Delta T$, in the sample. The analysis of the heat flow under these circumstances [30] shows that a plot of $\Delta T$ as a function of the inverse square root of the time, $1 / \sqrt{ } t$, is linear, and that the thermal conductivity, $\lambda$, can be determined from the extrapolated value of $\Delta T$ at infinite time $\left(1 / \sqrt{ }_{t}=0\right)$.

\subsubsection{FT-IR measurements}

For the Fourier transform infra-red (FT-IR) spectrometry studies, the treated BN samples were combined with the carrier, potassium bromide $(\mathrm{KBr})$ which had been previously dried and maintained in a desiccator, and the combination was crushed to a fine powder in a pestle and mortar. The resulting powder was moulded in a press at 10 tonnes into disc-shaped tablets 13 $\mathrm{mm}$ diameter and about $1 \mathrm{~mm}$ thick. A similar tablet consisting only of $\mathrm{KBr}$ was used for the background signal. The tablets were placed in the FT-IR instrument, Nicolet 6700, and 32 scans with a resolution of $4 \mathrm{~cm}^{-1}$ were made covering the mid-IR frequency range from $4000 \mathrm{~cm}^{-1}$ to $400 \mathrm{~cm}^{-1}$.

\subsubsection{Scanning Electron Microscopy (SEM)}

The scanning electron microscopy (SEM) studies were performed using the Zeiss Merlin FESEM microscope, with a resolution of $0.8 \mathrm{~nm}$ at $15 \mathrm{kV}$, equipped with an energy dispersive $\mathrm{X}$ ray (EDX) detector, Oxford LINCA X-Max, using Nordlys II analysis. The fracture surface of cured samples as well as the surface-modified BN particles alone were metallised and investigated by SEM to detect the presence or otherwise of the silane and $\mathrm{NaOH}$.

\subsubsection{Thermogravimetric analysis (TGA)}

Thermogravimetric analysis (TGA), which measures the weight loss of the sample as it is heated at a controlled rate over a prescribed temperature range, was performed in a Mettler-Toledo TGA/DSC1 equipped with a sample robot and Huber cryostat (precision $0.1^{\circ} \mathrm{C}$ ). The TGA/DSC was calibrated using indium with a dry air flow of $200 \mathrm{~mL} / \mathrm{min}$, and the experiments were 
performed with a dry nitrogen flow of $200 \mathrm{~mL} / \mathrm{min}$ at heating rates of 2 and $10 \mathrm{~K} / \mathrm{min}$ over a temperature range from $40{ }^{\circ} \mathrm{C}$ to $600{ }^{\circ} \mathrm{C}$.

\section{Results and Discussions}

\subsection{FTIR analysis}

Figure 2 shows the FT-IR spectra of untreated and treated BN $6 \mu \mathrm{m}$ platelets and $120 \mu \mathrm{m}$ agglomerates. The bands at $1369 \mathrm{~cm}^{-1}$ and approximately $800 \mathrm{~cm}^{-1}$ correspond to B-N stretching and bending vibrations [31], respectively, and are present in all the samples. The band at 3400 $\mathrm{cm}^{-1}$ can be attributed to $\mathrm{N}-\mathrm{H}$ and $-\mathrm{OH}$ stretching vibrations [31], and is evident in both of the untreated samples, BN6 and BN120, but with a greater intensity in the samples BN6-NaOH and BN120-NaOH, which have been $\mathrm{NaOH}$-treated. This suggests that additional $-\mathrm{OH}$ groups have been attached to these $\mathrm{NaOH}$-treated samples, which should be beneficial for the subsequent silane treatment. The band associated with the Si-O stretching vibrations should appear around $1100 \mathrm{~cm}^{-1}[7,9,27]$, and can be seen for the silane-treated sample BN6-Si4\%, as highlighted in Figure 2, which suggests that the silane coupling agent has successfully been attached to the BN6 platelets. On the other hand, the silane-treated BN120 agglomerates do not display the band at $1100 \mathrm{~cm}^{-1}$, indicating that the silane coupling agent has not been attached to these particles, as was anticipated from the consideration that they present very few edges for surface modification. These results suggest, therefore, that an enhancement on the thermal conductivity could be expected for the epoxy-BN composites filled with surface-modified BN6 platelets but not for those filled with the corresponding $120 \mu \mathrm{m}$ agglomerates. 


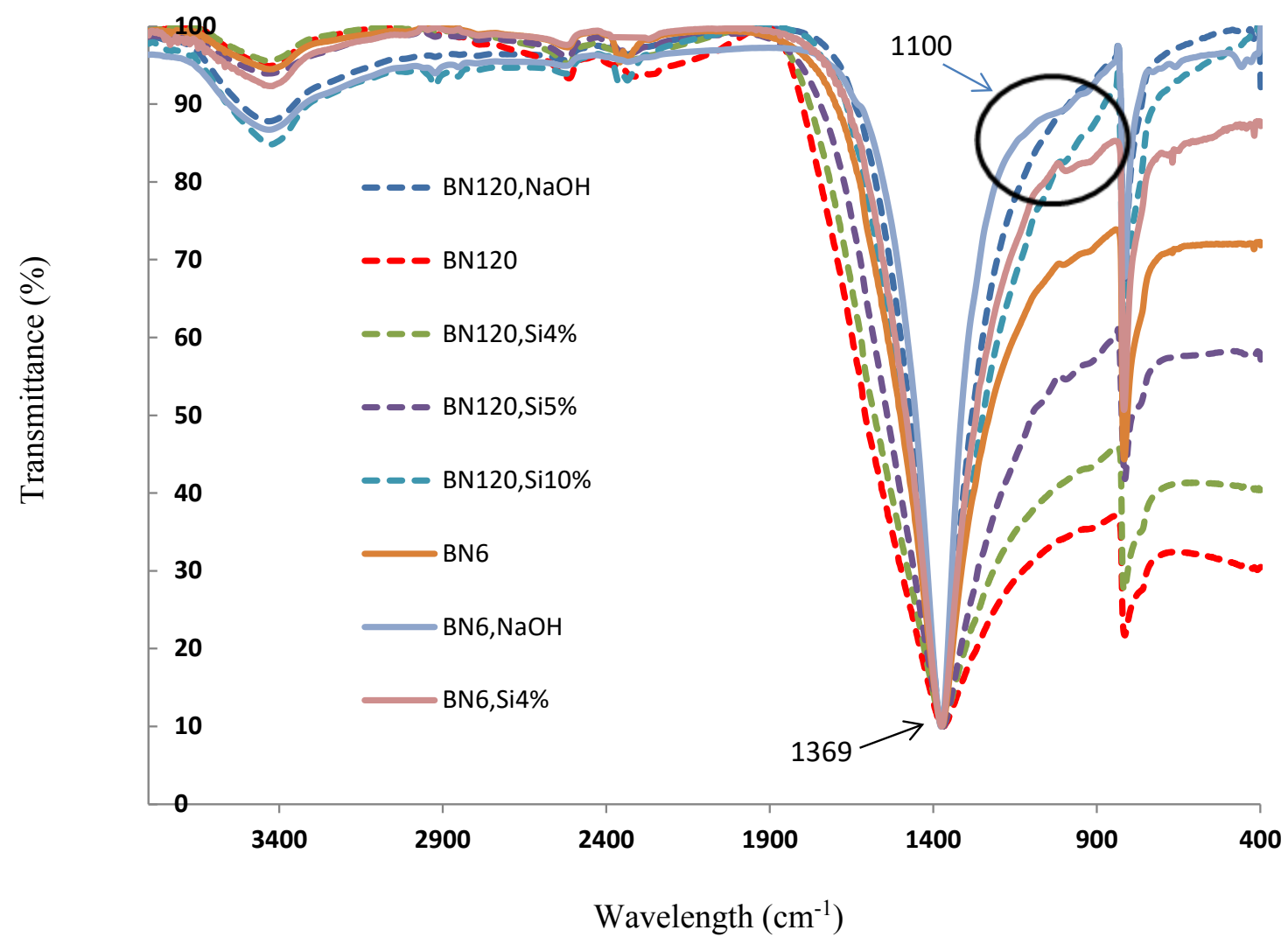

Figure 2. FT-IR spectra of treated and untreated BN particles.

\subsection{Thermo-gravimetric analysis (TGA)}

The thermal stability of epoxy-BN composites filled with untreated and treated BN 6 and 120 $\mu \mathrm{m}$ particles was studied by TGA. In particular, the residual weight at $600{ }^{\circ} \mathrm{C}$ was determined, and the results are given in Table 2. The residual weights of composites with 30,50 and $60 \mathrm{wt} \%$ of the untreated $\mathrm{BN}$ are independent of particle size, and very close to the values of $23.2 \pm 2 \%$, $38.9 \pm 1.6 \%$ and $48.1 \pm 1.3 \%$, respectively, calculated from the residual weight of the unfilled ETL system, $5 \pm 3 \%$, and that of the BN particles themselves, $97 \pm 2 \%$. For the composite system filled with the $120 \mu \mathrm{m}$ silane-treated agglomerates with the different proportions of silane, there is a very small increase in the residual weight in comparison with the composites filled with untreated particles, but the increase is only of the order of the experimental uncertainty. This can be seen in Table 2 and in Figure 3, where all the curves for the $30 \mathrm{wt} \%$ samples superpose 
approximately. For the system with $6 \mu \mathrm{m}$ platelets, the comparison has been made for 30, 50 and $60 \mathrm{wt} \% \mathrm{BN}$, and can be seen in Figure 4 and Table 2 as a small but systematic increase for the composites filled with silane-treated particles. It could be concluded from these observations that the silane-treated particles do indeed have some silane groups attached which result in a slightly higher residue, and that this is more marked for the $6 \mu \mathrm{m}$ platelets than for the $120 \mu \mathrm{m}$ agglomerates.

An additional comment should be made about the $6 \mu \mathrm{m}$ composites for which the $\mathrm{NaOH}$ surface treatment was applied before the silane. For this system, with $30 \mathrm{wt} \% \mathrm{BN}$, there is a very much larger increase in the residual weight: $43.4 \mathrm{wt} \%$ for the treated sample in comparison with 26.2 $\mathrm{wt} \%$ for the untreated sample. This suggests that there is a significant amount of the surface treatment which remains attached to the BN platelets for this sample, but, as will be shown below by SEM, this is not the case.

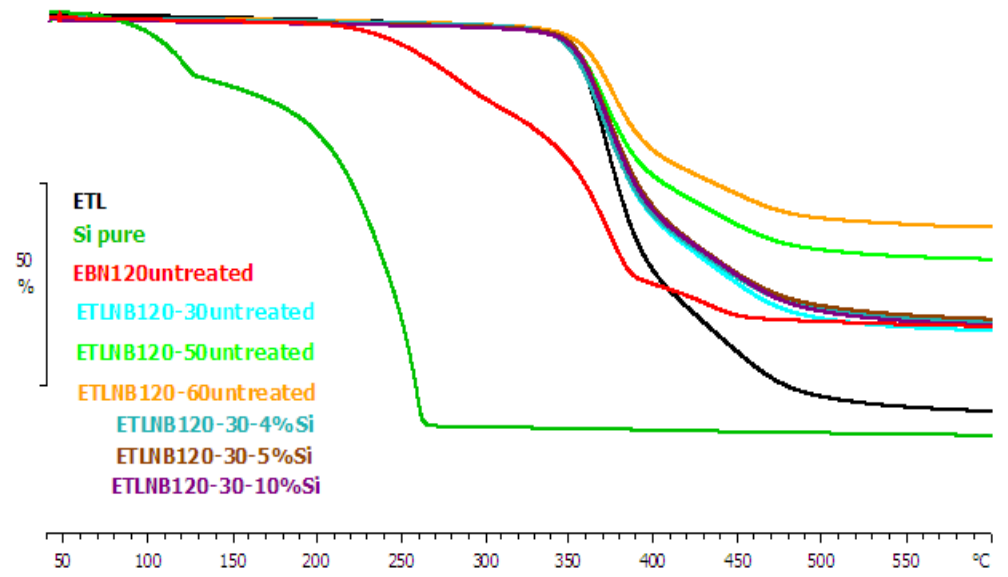

Figure 3. TGA for ETLBN120- $x$ system, untreated and treated, at $10 \mathrm{~K} / \mathrm{min}$. 


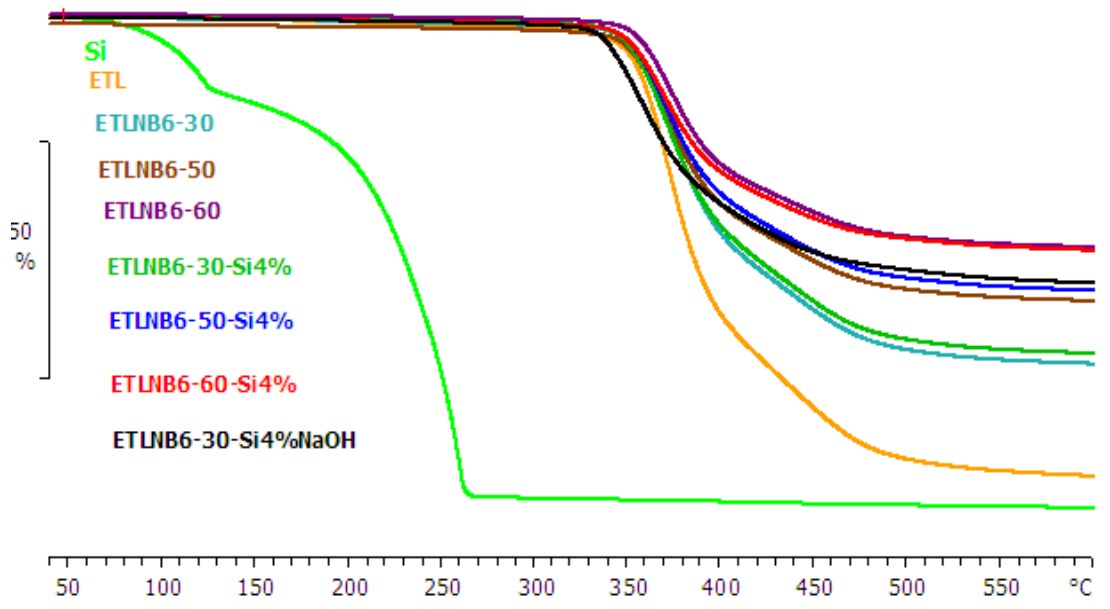

Figure 4. TGA for ETLBN6- $x$ system, untreated and treated at $10 \mathrm{~K} / \mathrm{min}$.

Table 2. TGA results for untreated and treated composites filled with $6 \mu \mathrm{m}$ and $120 \mu \mathrm{m} \mathrm{BN}$ particles.

\begin{tabular}{|l|l|}
\hline Sample & Residual weight (\%) \\
\hline ETLBN120-30 & 23.0 \\
\hline ETLBN120-50 & 41.0 \\
\hline ETLBN120-60 & 48.0 \\
\hline ETLBN120-30-Si4\% & 25.0 \\
\hline ETLBN120-30-Si5\% & 26.1 \\
\hline ETLBN120-30-Si10\% & 26.0 \\
\hline ETLBN6-30 & 26.2 \\
\hline ETLBN6-50 & 41.0 \\
\hline ETLBN6-60 & 50.4 \\
\hline ETLBN6-30-Si4\% & 28.5 \\
\hline ETLBN6-50-Si4\% & 41.8 \\
\hline ETLBN6-60-Si4\% & 50.4 \\
\hline ETLBN6-30-NaOH-Si4\% & 43.4 \\
\hline
\end{tabular}




\subsection{Differential Scanning Calorimetry (DSC)}

Typical non-isothermal DSC cure curves for the composite system ETLBN120-30 with untreated $120 \mu \mathrm{m} \mathrm{BN}$ agglomerates, and for the same composite system with treated $120 \mu \mathrm{m}$ particles with 4, 5 and $10 \%$ of silane coupling agent, are shown in Figure 5, and the values of the peak temperature, $T_{\mathrm{p}}$, and the heat of reaction, $\Delta H$, are given in Table 3 . It can be seen that both $T_{\mathrm{p}}$ and $\Delta H$ remain essentially constant, independent of the silane treatment and of the silane concentration. The slightly lower values of these parameters for the $5 \%$ silane concentration is not believed to be significant, and in fact correlates with a slightly lower values of the glass transition temperature of the fully cured system, $T_{\mathrm{g} \infty}$, which suggests that this sample might not have been fully cured.

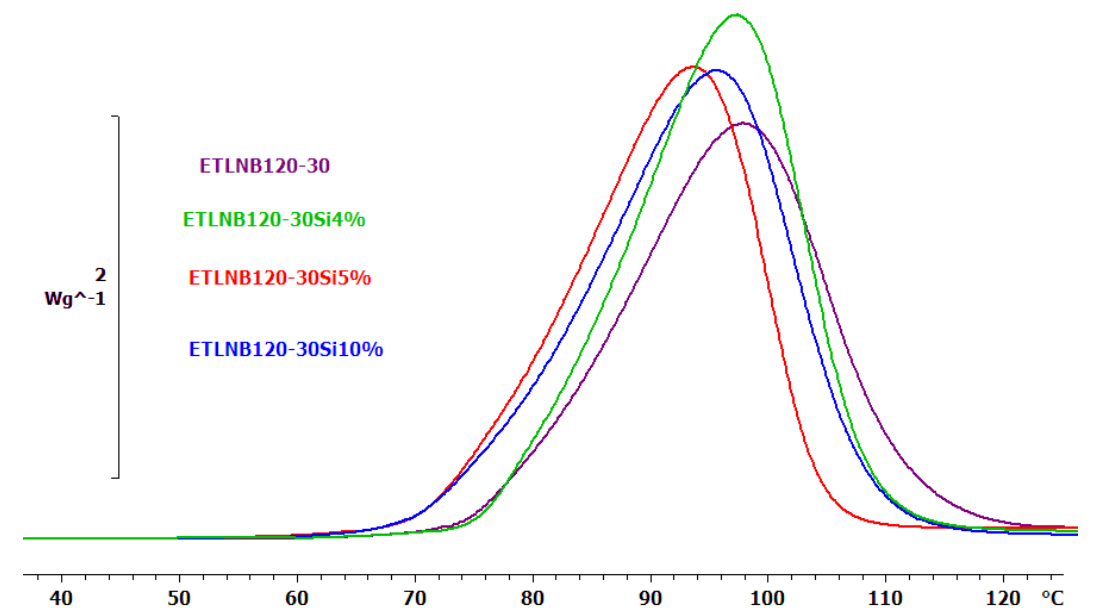

Figure 5. Non-isothermal cure for composites with $120 \mu \mathrm{m}$ agglomerates, at $10 \mathrm{~K} / \mathrm{min}$.

The corresponding non-isothermal cure curves for epoxy-thiol composites with $6 \mu \mathrm{m}$ platelets with $30 \mathrm{wt} \%$ content of BN are shown in Figure 6, including untreated particles, particles treated with $4 \%$ silane coupling agent, and those treated with $4 \%$ silane following the $\mathrm{NaOH}$ treatment. In contrast with the results obtained for the composites with $120 \mu \mathrm{m}$ agglomerates shown in Figure 5, here the silane treatment has a significant effect on the cure kinetics; this is consistent with the hypothesis that the surface treatment might be effective for platelet-shaped particles but will not be effective for agglomerates for which there are very few active edges. For these 
composites with $6 \mu \mathrm{m}$ platelets, the silane appears to accelerate the reaction, the peak temperature $T_{\mathrm{p}}$ being about $4{ }^{\circ} \mathrm{C}$ lower after either of the surface treatments. This observation is consistent also for composites with higher $\mathrm{wt} \%$ of $\mathrm{BN}$, namely 50 and $60 \mathrm{wt} \%$, as can be seen from the results given in Table 3.

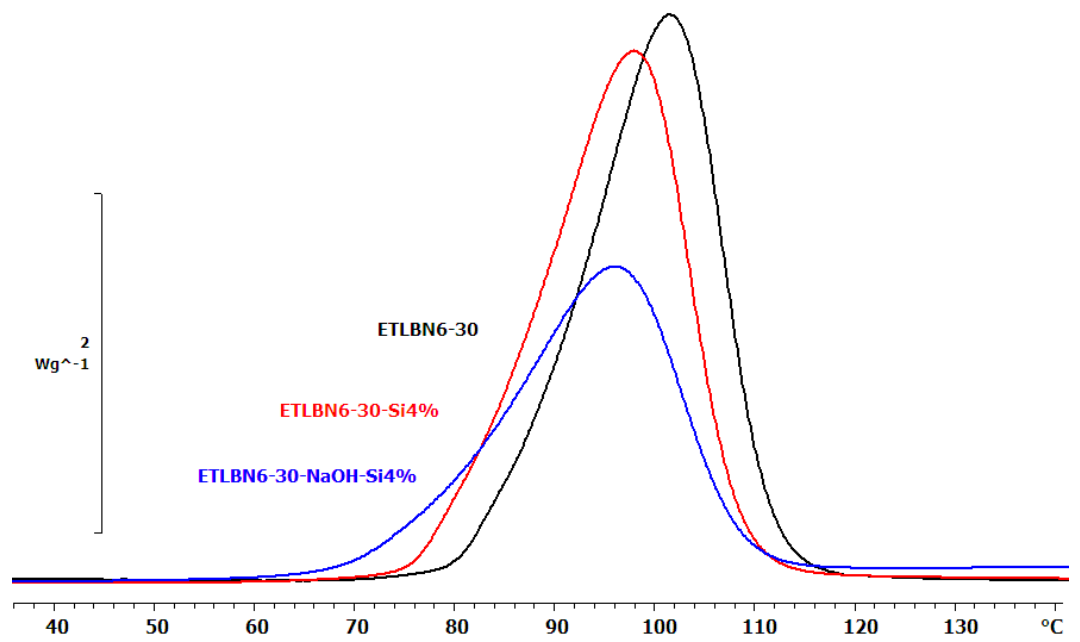

Figure 6. Non-isothermal cure for composites with $6 \mu \mathrm{m}$ platelets, at $10 \mathrm{~K} / \mathrm{min}$.

It can also be seen form Figure 6 and from Table 3 that the heat of reaction decreases significantly for the sample treated with both $\mathrm{NaOH}$ and silane. Since the heat of reaction is calculated per unit of total mas of sample, this suggests that there is significantly more unreactive matter in this composite sample, which would be consistent with the TGA result presented above, where the residue was significantly larger than for the untreated sample.

It should be noted that the glass transition temperature of the fully cured systems, $T_{\mathrm{g} \infty}$, remains essentially constant, as can be seen from the values in Table 3, which implies that the cured network structure is unaffected by the surface modification of the BN particles. On the other hand, the cure kinetics does appear to be influenced by the surface treatment for the $6 \mu \mathrm{m}$ platelets but not for the $120 \mu \mathrm{m}$ agglomerates, in accordance with our hypothesis that there must be reactive edges available for successful surface modification to occur. 
Table 3. DSC results at $10 \mathrm{~K} / \mathrm{min}$ for untreated and treated epoxy-thiol composites with $6 \mu \mathrm{m}$ and $120 \mu \mathrm{m} \mathrm{BN}$ particles.

\begin{tabular}{|c|c|c|c|}
\hline Sample & $\Delta H(\mathrm{~kJ} / \mathrm{ee})$ & $T_{\mathrm{P}}\left({ }^{\circ} \mathrm{C}\right)$ & $T_{\mathrm{g} \infty}\left({ }^{\circ} \mathrm{C}\right)$ \\
\hline ETLBN120-30 & 112 & 97.9 & 52.8 \\
\hline ETLBN120-30-Si4\% & 121 & 97.3 & 53.3 \\
\hline ETLBN120-30-Si5\% & 112 & 93.5 & 50.7 \\
\hline ETLBN120-30-Si10\% & 125 & 95.5 & 53.3 \\
\hline ETLBN6-30 & 128 & 101.6 & 52.1 \\
\hline ETLBN6-50 & 128 & 103.1 & 52.0 \\
\hline ETLBN6-60 & 126 & 109.5 & 52.1 \\
\hline ETLBN6-30-Si4\% & 124 & 96.1 & 53.2 \\
\hline ETLBN6-50-Si4\% & 120 & 98.7 & 52.6 \\
\hline ETLBN6-60-Si4\% & 114 & 101.1 & 52.4 \\
\hline ETLBN6-30-NaOH-Si4\% & 86 & 96.1 & 53.2 \\
\hline
\end{tabular}

\subsection{Thermal Conductivity Measurements}

The thermal conductivities, $\lambda$, of the different samples, measured by the Transient Hot Bridge method, are plotted as a function of the vol \% BN in Figure 7. The first observation that can be made is that the thermal conductivity increases with $\mathrm{BN}$ content, and also as the particle size increases; both of these effects are expected. The highest thermal conductivity is about 3.0 $\mathrm{W} / \mathrm{mK}$ for composites filled with nearly $35 \mathrm{vol} \%$ of the untreated BN $120 \mu \mathrm{m}$ agglomerates.

Second, the purpose of the surface treatments was to improve the interface between BN particles and epoxy matrix in order to increase the thermal conductivity of the composites. The hypothesis was that the surface treatment would be effective for the $6 \mu \mathrm{m}$ BN platelets but not for the 120 $\mu \mathrm{m}$ agglomerates, but this has not been demonstrated in most cases. That the surface treatment is not effective for the $120 \mu \mathrm{m}$ agglomerates can indeed be confirmed from the results in Figure 7, where the thermal conductivity after surface treatment for the $30 \mathrm{wt} \% \mathrm{BN}$ system decreases from $1.06 \mathrm{~W} / \mathrm{mK}$ for the untreated sample to $0.77 \mathrm{~W} / \mathrm{mK}$ for the treated sample, a decrease of nearly $30 \%$. In comparison, for the same $30 \mathrm{wt} \%$ of the $6 \mu \mathrm{m} \mathrm{BN}$ platelets, the effect of both of the surface treatments is to increase the thermal conductivity, again in agreement with our hypothesis, but with some qualifications. The larger increase, from $0.67 \mathrm{~W} / \mathrm{mK}$ for the untreated 
sample to $0.98 \mathrm{~W} / \mathrm{mK}$ occurs for sample ETLBN6-30-Si4\%, involving only the silane treatment, for which there was only a small increase in the residue by TGA. The smaller increase, to 0.87 W/mK occurs for sample ETLBN6-30-NaOH-Si, involving both $\mathrm{NaOH}$ and silane treatments, for which there was a substantial increase in the residue by TGA, suggesting a greater effect of this surface treatment. On the other hand, the DSC cure kinetics, as quantified by the peak temperature $T_{\mathrm{p}}$, does not indicate any significant difference between these two treatment procedures, which leaves some doubts about their efficacies.

When the thermal conductivities of the surface-treated $6 \mu \mathrm{m}$ composites with higher BN contents are measured, however, the effect of the surface treatment is found to be negative, resulting in lower values of the thermal conductivity than those obtained for composites fabricated with the untreated platelets. This can clearly be seen in Figure 7 for the $50 \mathrm{wt} \%$ and $60 \mathrm{wt} \% \mathrm{BN}$ contents, corresponding to 25.7 and $34.2 \mathrm{vol} \%$, respectively. The dramatic decrease in the thermal conductivity of these samples is unexpected, and the reason for this must be sought in the microstructural examination by SEM.

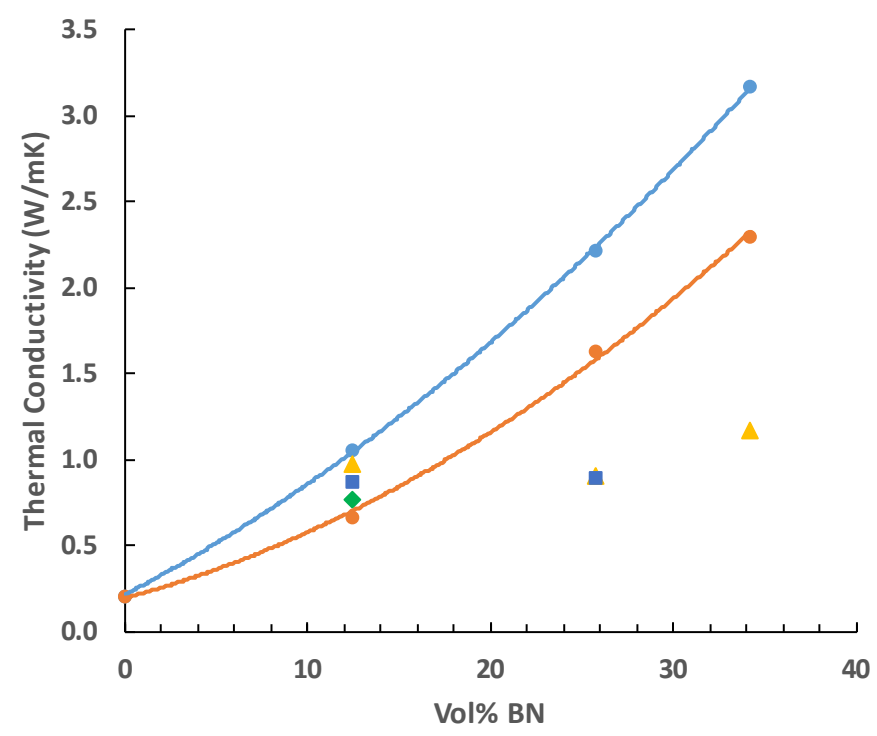

Figure 7. Thermal conductivity as a function of vol $\% \mathrm{BN}$ for the composites with untreated and treated BN $6 \mu \mathrm{m}$ and $120 \mu \mathrm{m}$ particles: blue circles, ETLBN120-30; orange circles, ETLBN630; green diamond, ETLBN120-30-Si4\%; yellow triangle, ETLBN6-30-Si4\%; blue square, ETLBN6-30-NaOH-Si. 


\subsection{Scanning Electron Microscopy (SEM)}

In order to obtain a clearer picture of the presence or otherwise of the silane coupling agent on the BN particles, the samples were examined by SEM with atomic analysis by EDX. This was done both for the treated particles and for the fracture surfaces of the fully cured composites. The $120 \mu \mathrm{m}$ agglomerate particles treated with $4 \%$ and $5 \%$ silane both gave spectra with the same atomic percentages (at $\%$ ): B $51.8 \% \pm 0.7 \%, \mathrm{~N} 47.2 \% \pm 0.6 \%$, and $\mathrm{O}$ about $1 \%$, with no signal from Si. Likewise, the fracture surfaces of cured samples with $30 \mathrm{wt} \% \mathrm{BN}$ and with $4 \%$ and 5\% silane treatment, such as that shown in Figure 8 for the 5\% silane content, did not show the presence of Si. For example, the spectrum at position A, on the edge of one of the platelets that constitute the $120 \mu \mathrm{m}$ agglomerate, indicated 49.9 at $\%$ and 45.1 at $\%$ of $\mathrm{B}$ and $\mathrm{N}$, respectively, with 1.3 at $\% \mathrm{~S}$, from the thiol, and 3.3 at $\%$ Au background. A similar spectrum at position $\mathrm{B}$, on the surface of one of the large faces of the same particle, indicated a larger amount of sulphur, 11.0 at $\%$, as a consequence of the presence of a greater amount of the epoxy-thiol matrix. No Si was detected in any of the $120 \mu \mathrm{m}$ treated particles or in the corresponding cured composites, supporting the hypothesis that the surface treatment does not result in the attachment of the coupling agent to the surface of these agglomerates, and hence does not result in any increase in the thermal conductivity.

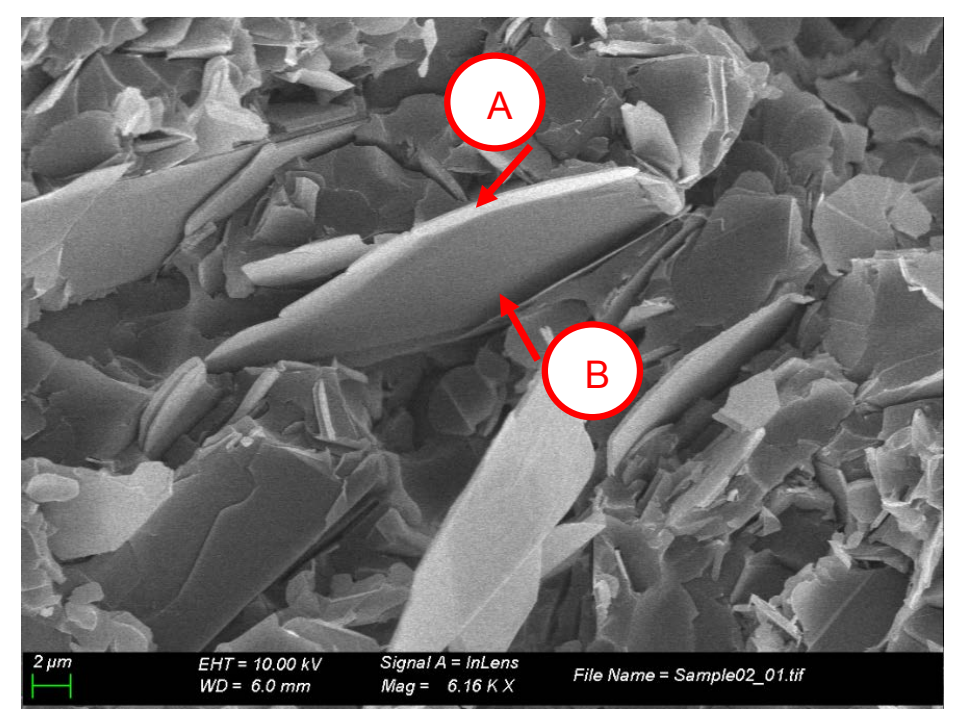

Figure 8. SEM micrograph of fracture surface of ETLBN120-30-Si5\%. 
The fracture surfaces of the cured samples with $6 \mu \mathrm{m}$ BN platelets treated with $4 \%$ silane, such as that shown in Figure 9 for the $30 \mathrm{wt} \%$ BN composite, likewise did not show the presence of Si. A spectrum from the sample of Figure 9 in a region consisting mainly of matrix gives 79.6 at $\% \mathrm{C}, 8.9$ at $\% \mathrm{O}$ and 7.9 at $\% \mathrm{~S}$, while a region close to a $\mathrm{BN}$ particle gives 41.8 at $\% \mathrm{~B}, 30.2$ at $\% \mathrm{~N}$ and 22.4 at $\% \mathrm{C}$, with no signal from $\mathrm{Si}$. The same observation is made for the composites with $50 \mathrm{wt} \%$ and $60 \mathrm{wt} \%$ of the silane treated $6 \mu \mathrm{m}$ platelets.

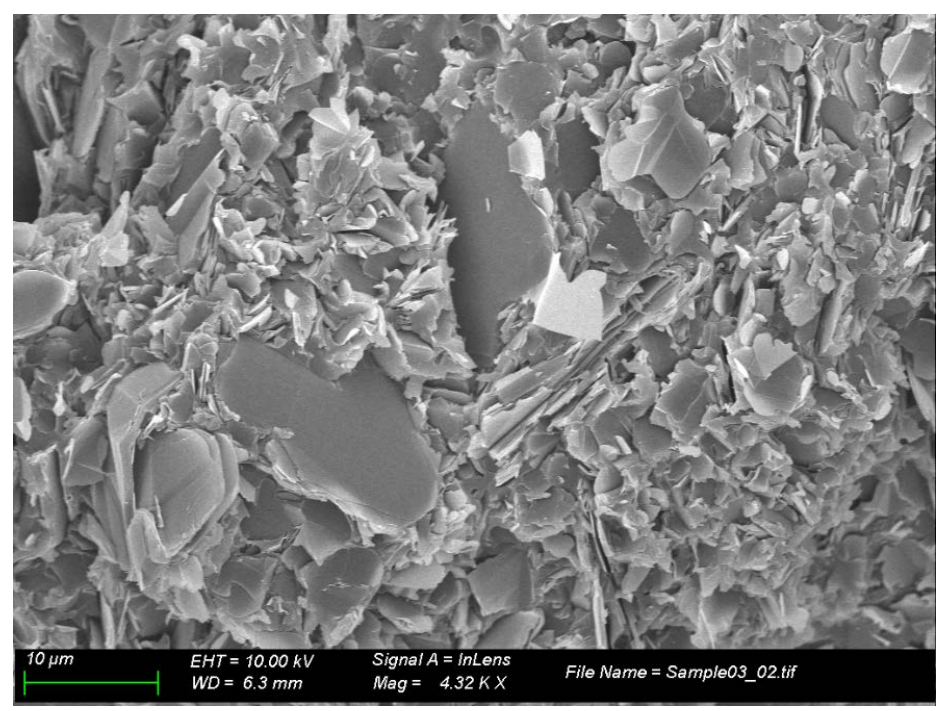

Figure 9. SEM micrograph of fracture surface of ETLBN6-30-Si4\%.

For the composites ETLBN6-30-NaOH-Si4\%, with $30 \mathrm{wt} \%$ of the $\mathrm{NaOH}-$ and silane-treated 6 $\mu \mathrm{m}$ platelets, though, there was sometimes, but not always, a significant Si peak in the spectrum, depending on the region under investigation. For example, a region of this ETLBN6-30-NaOH$\mathrm{Si} 4 \%$ sample is shown in Figure 10a, and the mapping of the Si for this region is shown in Figure 10b, with the complete spectrum shown in Figure 10c. It can be seen from Figure 10c that there is a significant proportion of $\mathrm{Si}$ (peak at $\sim 1.75 \mathrm{keV}$ ) in the signal. This is consistent with the larger residue observed by TGA for this sample, suggesting that there is a greater amount of silane coupling agent attached to the BN particles than there is for the other treatments. However, the mapping of Figure $10 \mathrm{~b}$ indicates that the $\mathrm{Si}$ is concentrated in a rather localised area. If the silane were distributed uniformly on the surfaces of the BN platelets, then a more uniform distribution would be anticipated from this mapping. In order to study this in more detail, the 
EDX analysis was performed on the treated $\mathrm{BN}$ particles themselves rather than on the fracture surface of the cured system.
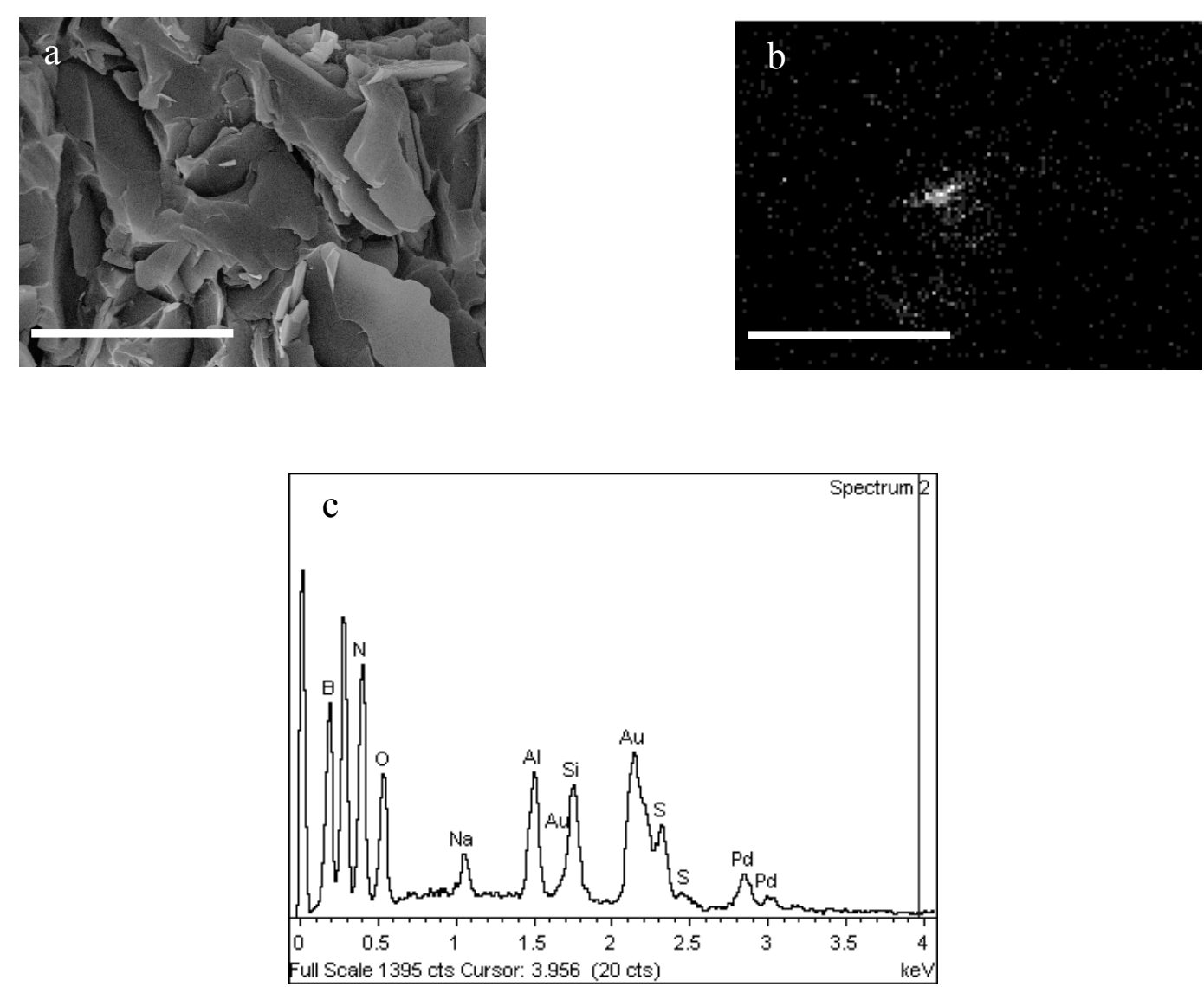

Figure 10. (a) SEM micrograph of fracture surface of ETLBN6-30-NaOH-Si4\%, scale bar $6 \mu \mathrm{m}$; (b) mapping of Si for the image of Figure 10a, scale bar $6 \mu \mathrm{m}$; (c) EDX spectrum from fracture surface shown in Figure 10a.

Figure 11a shows an individual BN particle from the batch which nominally consists of $6 \mu \mathrm{m}$ platelets. This particle has the appearance of an agglomerate and has a size of approximately 12 $\mu \mathrm{m}$; this has already been commented on in respect of the as-received materials, and illustrated in Figure 1a. An EDX scan through this particle is shown in Figure 11a, and reproduced in Figure $11 \mathrm{~b}$, from which it can be seen that, within the particle, there is no significant increase in the Si signal, suggesting that there is no significant amount of silane coupling agent attached to this 
particle. However, Figure 10c indicates that there is overall a significant presence of $\mathrm{Si}$ in the composites fabricated with these treated particles, and the question is where does this come from.
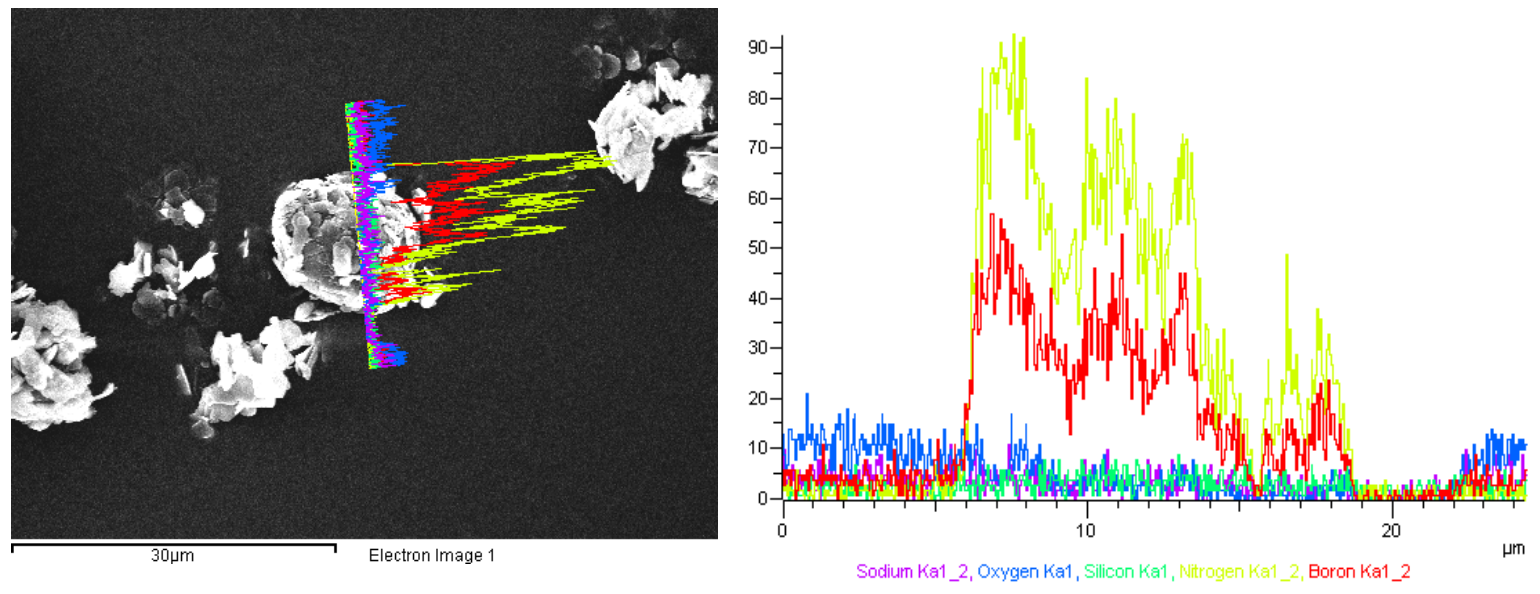

Figure 11. (a) SEM micrograph of individual ETLBN6-30-NaOH-Si4\% particle, scale bar 30 $\mu \mathrm{m}$; (b) EDX scan through particle: red, B; light green, N; blue, O; purple, Na; cyan, Si.

To answer this question, another particle is examined by EDX, and is shown in Figure 12. The spectrum shows that this particle does not consist of $\mathrm{BN}$, but contains a large amount of $\mathrm{Si}$, and this provides the explanation for our observations. Rather than attaching themselves to the BN particle surfaces or edges, the silane coupling agent groups together to form what could be POSSlike particles, which is the particle seen in Figure 12. These are relatively large particles (the one in Figure 12 is about $7 \mu \mathrm{m}$ across), and remain mixed with the BN particles after the surface treatment, and are not filtered away. They contribute to the increased residue in the TGA experiments, and presumably in some way influence also the DSC kinetics, but they do not in general contribute to the thermal conductivity, which as a consequence decreases for the $50 \mathrm{wt} \%$ and $60 \mathrm{wt} \%$ samples..
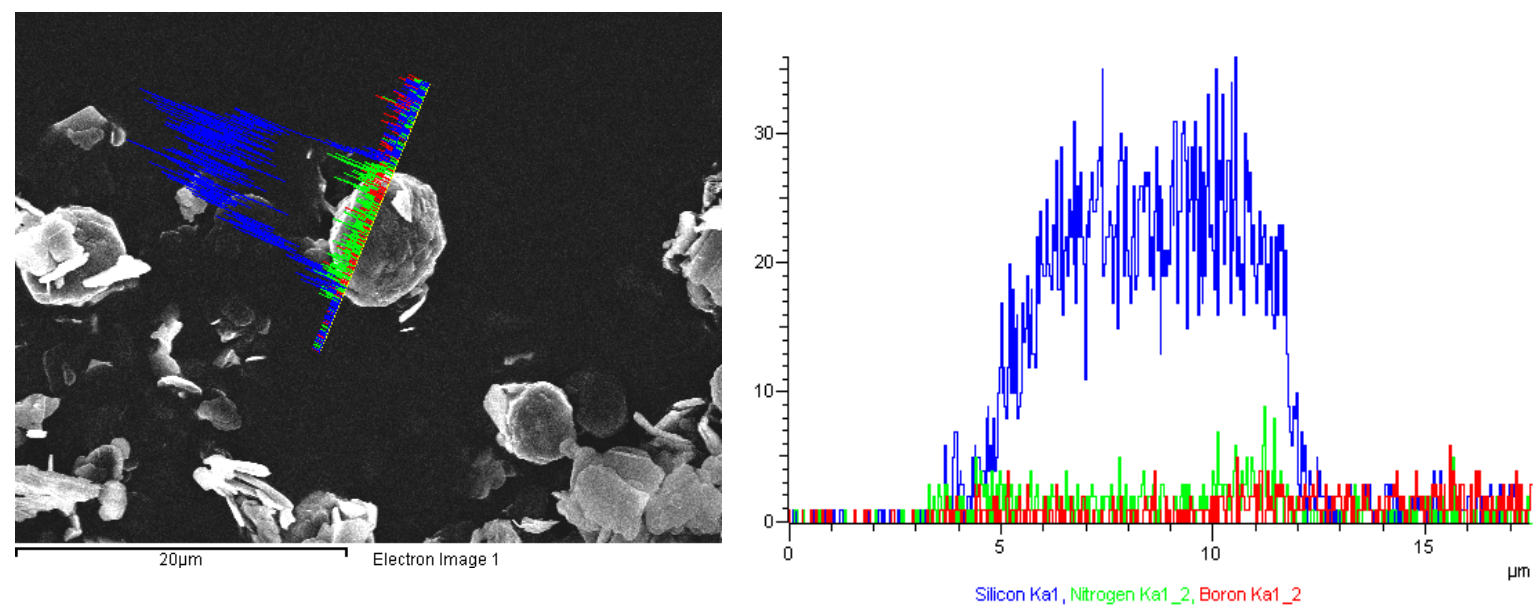
Figure 12. (a) SEM micrograph of individual ETLBN6-30-NaOH-Si4\% particle, scale bar 20 $\mu \mathrm{m}$; (b) EDX scan through particle: red, B; light green, N; blue, Si.

The reason why the thermal conductivity of the $30 \mathrm{wt} \% \mathrm{BN}$ system with $6 \mu \mathrm{m}$ particles increases, as seen in Figure 7, rather than decreases as the above interpretation would predict, remains unclear, and requires further investigation. Indeed, our conclusion is that the procedure of surface treating the BN particles advocated by many authors $[7,9,13,16-19,28]$ does not work for our particles, and yet these same authors report increases in the thermal conductivity of their composites. One possible explanation is that the supposedly $6 \mu \mathrm{m}$ platelets are in fact in the major part agglomerates, for which we would not anticipate an increase in thermal conductivity after surface treatment, and which has been demonstrated for the $120 \mu \mathrm{m}$ agglomerates here. Further work is currently under way to investigate the surface treatment of BN particles which are truly in the form of platelets, and of different dimensions.

\section{Conclusions}

The surface treatment of two different types of BN particles, one nominally in the form of platelets and the other in the form of agglomerates, has been investigated as a procedure for enhancing the thermal conductivity of epoxy-thiol composites filled with BN. The surface treatments were intended to attach silane groups to the $\mathrm{BN}$ particles to improve the interface between the $\mathrm{BN}$ particles and the epoxy-thiol matrix, and the hypothesis was that this procedure would be effective for the platelets but not for the agglomerates. The effectiveness of this surface treatment was assessed by FTIR, TGA and DSC, all of which suggested that the surface of the platelets was indeed modified whereas that of the agglomerates was not. However, the thermal conductivity of the cured systems was not generally enhanced; only in one isolated case for the platelets was there an increase in the thermal conductivity, while for all the other samples there was a significant decrease. SEM studies showed that there was a significant proportion of the nominally platelet-type particles that were in fact in the form of agglomerates, and that the silane did not attach to the BN particles but instead formed separate POSS-like particles. These POSSlike particles contributed to the TGA and FTIR signals which suggested incorrectly that the silane groups had been attached to the BN particles. The conclusion is that, for effective surface treatment, it is essential that the $\mathrm{BN}$ particles be truly in the form of platelets. 


\section{References}

[1] Chen H, Ginzburg VV, Yang J, Yang Y, Liu W, Huang Y, Du L, Chen B. Thermal conductivity of polymer-based composites: fundamentals and applications. Prog Polym Sci. 2016;59:41-85.

[2] Huang X, Jiang P, Tanaka T. A review of dielectric polymer composites with high thermal conductivity. IEEE Electrical Insulation Magazine. 2011;27:8-16.

[3] Hutchinson JM, Román F, Folch A. Epoxy-thiol systems filled with boron nitride for high thermal conductivity applications. Polymers. 2018;10:340 (18pp).

[4] Yung KC, Wang J, Yue TM. Thermal management for boron nitride filled metal core printed circuit board. J Comp Mater. 2008;42:2615-2627.

[5] Zhu BL, Ma J, Wu J, Yung KC, Xie CS. Study on the properties of the epoxy-matrix composites filled with thermally conductive AlN and BN ceramic particles. J Appl Polym Sci. 2010;118:2754-2764.

[6] Hong J-P, Yoon S-W, Hwang T, Oh J-S, Hong S-C, Lee Y, Nam J-D. High thermal conductivity epoxy composites with bimodal distribution of aluminum nitride and boron nitride fillers. Thermochim Acta 2012;537:70-75.

[7] Kim K, Kim M, Hwang Y, Kim J. Chemically modified boron nitride-epoxy terminated dimethylsiloxane composite for improving the thermal conductivity. Ceram Int. 2014;40:20472056.

[8] Donnay M, Tzavalas S, Logakis E. Boron nitride filled epoxy with improved thermal conductivity and dielectric breakdown strength. Comp Sci Technol. 2015;110:152-158.

[9] Chung S-L, Lin J-S. Thermal conductivity of epoxy resin composites filled with combustion synthesized h-BN particles. Molecules 2016;21:670 (11pp)

[10] Kim K, Kim M, Kim J. Thermal and mechanical properties of epoxy composites with a binary particle filler system consisting of aggregated and whisker type boron nitride particles. Comp Sci Technol. 2014;103:72-77.

[11] Gaska K, Rybak A, Kapusta C, Sekula R, Siwek A. Enhanced thermal conductivity of epoxy-matrix composites with hybrid fillers. Polym Adv Technol. 2015;26:26-31. 
[12] Huang L, Zhu P, Li G, Zhou F, Lu D, Sun R, Wong C. Spherical and flake-like BN filled epoxy composites: morphological effect on the thermal conductivity, thermo-mechanical and dielectric properties. J Mater Sci: Mater Electron. 2015;26:3564-3572.

[13] Permal A, Devarajan M, Hung HL, Zahner T, Lacey D, Ibrahim K. Thermal and mechanical properties of epoxy composite filled with binary particle system of polygonal aluminum oxide and boron nitride platelets. J Mater Sci. 2016;51:7415-7426.

[14] Hong J-P, Yoon S-W, Hwang T-S, Lee Y-K, Won S-H, Nam J-D. Interphase control of boron nitride/epoxy composites for high thermal conductivity. Korea-Australia Rheol J. 2010;22:259-264.

[15] Wattanakul K, Manuspiya H, Yanumet N. Thermal conductivity and mechanical properties of BN-filled epoxy composite: effects of filler content, mixing conditions, and BN agglomerate size. J Comp Mater. 2011;45:1967-1980.

[16] Teng C-C, Ma C-CM, Chiou K-C, Lee T-M, Shih Y-F. Synergetic effect of hybrid boron nitride and multi-walled carbon nanotubes on the thermal conductivity of epoxy composites. Mater. Chem. Phys. 2011;126:722-728.

[17] Wattanakul K, Manuspiya H, Yanumet N. Effective surface treatments for enhancing the thermal conductivity of BN-filled epoxy composite. J Appl Polym Sci. 2011;119:3234-3243.

[18] Hou J, Li G, Yang N, Qin L, Grami ME, Zhang Q, Wang N, Qu X. Preparation and characterization of surface modified boron nitride epoxy composites with enhanced thermal conductivity. RSC Adv. 2014;4:44282-44290.

[19] Zhou W, Zuo J, Zhang X, Zhou A. Thermal, electrical, and mechanical properties of hexagonal boron nitride-reinforced epoxy composites. J Comp Mater. 2014;48:2517-2526.

[20] Xu Y, Chung DDL. Increasing the thermal conductivity of boron nitride and aluminum nitride particle epoxy-matrix composites by particles surface treatments. Comp Interf. 2000;7:243-256.

[21] Jang I, Shin K-H, Yang I, Kim H, Kim J, Kim W-H, Jeon S-W, Kim J-P. Enhancement of thermal conductivity of BN/epoxy composite through surface modification with silane coupling agents. Coll Surf A: Physicochem. Eng. Aspects 2017;518:64-72.

[22] Fu J, Shi L, Zhang D, Zhong Q, Chen Y. Effect of nanoparticles on the performance of thermally conductive epoxy adhesives. Polym Eng Sci. 2010;50:1809-1818. 
[23] Tanaka T, Wang Z, lizuka T, Kozako M, Ohki Y. High thermal conductivity epoxy/BN composites with sufficient dielectric breakdown strength. 2011 Annual Report Conference on Electrical Insulation and Dielectric Phenomena, Vols 1 and 2, IEEE, NY, USA, ISBN:978-14577-0986-9, pp 691-694.

[24] Gu J, Zhang Q, Dang J, Xie C. Thermal conductivity epoxy resin composites filled with boron nitride. Polym Adv Technol. 2012;23:1025-1028.

[25] Yu J, Huang X, Wu C, Wu X, Wang G, Jiang P. Interfacial modification of boron nitride nanoplatelets for epoxy composites with improved thermal properties. Polymer 2012;53:471480 .

[26] Qu T, Yang N, Hou J, Li G, Yao Y, Zhang Q, He L, Wu D, Qu X. Flame retarding epoxy composites with poly(phosphazene-co-bisphenol A)-coated boron nitride to improve thermal conductivity and thermal stability. RSC Adv. 2017;7:6140-6151.

[27] Kim K, Kim J. Fabrication of thermally conductive composite with surface modified boron nitride by epoxy wetting method. Ceram Int. 2014;40:5181-5189.

[28] Ishida H. Surface treated boron nitride for forming a low viscosity high thermal conductivity polymer based boron nitride composition and method. US Patent 6160042, 2000.

[29] Hutchinson JM, Román F, Cortés P, Calventus Y. Epoxy composites filled with boron nitride and aluminium nitride for improved thermal conductivity. Polimery 2017;62:560-566.

[30] Hammerschmidt U, Meier V. New Transient Hot-Bridge sensor to measure thermal conductivity, thermal diffusivity, and volumetric specific heat. Int J Thermophys. 2006;27:840865 .

[31] Fang L, Wu C, Qian R, Xie L, Yang K, Jiang P. Nano-micro structure of functionalized boron nitride and aluminum oxide for epoxy composites with enhanced thermal conductivity and breakdown strength. RSC Adv. 2014;4:21010-21017. 